\title{
Associations of single nucleotide polymorphisms in the adiponectin gene with adiponectin levels and cardio-metabolic risk factors in patients with cancer
}

\author{
Rasha Mazen Al Khaldi ${ }^{\mathrm{a}}$, Fahd Al Mulla ${ }^{\mathrm{a}}$, Shafika Al Awadhi ${ }^{\mathrm{b}}$, Kusum Kapila ${ }^{\mathrm{a}}$ and \\ Olusegun A. Mojiminiyi ${ }^{\mathrm{a}, *}$ \\ ${ }^{a}$ Department of Pathology, Kuwait University, Safat, Kuwait \\ ${ }^{\mathrm{b}}$ Department of Medicine, Faculty of Medicine, Kuwait University, Safat, Kuwait
}

\begin{abstract}
Objectives: The aims of this study are to (1) study the influence of polymorphisms in adiponectin gene on adiponectin levels and potential associations with breast, prostate and colon cancer; (2) investigate the associations of adiponectin levels with other adipokines and breast, prostate and colon cancers.

Subjects: We measured fasting adiponectin, leptin, insulin, Sex steroids in 132 (66 females, 66 males) cancer patients and 68 age and sex matched apparently healthy subjects. Body Mass Index (BMI) and waist circumference were used as indices of obesity. Insulin Resistance was assessed using Homeostasis Model Assessment (HOMA). Three single nucleotide polymorphisms (SNP rs182052 (G-10066-A), SNP rs1501299 (276G > T), SNP rs224176 (45T > G) in adiponectin gene were studied using Real Time Polymerase Chain Reaction.

Results: GG genotype of SNP rs 1501299 was significantly associated with higher levels of adiponectin $(\mathrm{OR}=1.2,95 \% \mathrm{CI}(1.03-$ $1.3), p=0.02)$; breast $(\mathrm{OR}=8.6,95 \% \mathrm{CI}(1.03-71), p=0.04)$, colon cancers $(\mathrm{OR}=12,95 \% \mathrm{CI}(1.2-115), p=0.03)$. GT genotype was also associated significantly with colon cancer $(\mathrm{OR}=2.6,95 \% \mathrm{CI}(1.1-6), p=0.03)$. However SNP rs224176 was associated with only breast cancer.

Conclusion: Our results demonstrate that adiponectin gene SNP rs 1501299 and SNP rs224176 may be the predisposing factors in some cancers but our results differ from what has been reported in other populations suggesting a complex relationship between genetic variations and phenotypic adiponectin levels.
\end{abstract}

Keywords: Adiponectin gene, SNPs, cancer, insulin resistance, adipokines

List of Abbreviations

$\begin{array}{ll}\text { SNPs } & \text { Single Nucleotide Polymorphisms } \\ \text { KCCC } & \text { Kuwait Cancer Control Center } \\ \text { BMI } & \text { Body Mass Index } \\ \text { ELISA } & \text { Enzyme Linked Immunosorbent Assay } \\ \text { FSH } & \text { Follicle Stimulating Hormone } \\ \text { LH } & \text { Luteinizing hormone }\end{array}$

SNPs Single Nucleotide Polymorphisms

BMI Body Mass Index

FSH Follicle Stimulating Hormone

LH Luteinizing hormone

$\begin{array}{ll}\text { SHBG } & \text { Sex Hormone Binding Globulin } \\ \text { HOMA } & \text { Homeostasis model assessment } \\ \text { DNA } & \text { Deoxyribonucleic acid } \\ \text { RNA } & \text { Ribonucleic acid } \\ \text { AD } & \text { Allelic Discrimination } \\ \text { CI } & \text { Confidence Interval } \\ \text { OR } & \text { Odds Ratio } \\ \text { ANOVA } & \text { One-way analysis of variance } \\ \text { SPSS } & \text { Statistical Package for Social Sciences } \\ \text { mRNA } & \text { messenger ribose nucleic acid }\end{array}$

\section{Introduction}

${ }^{*}$ Corresponding author: Dr. O.A. Mojiminiyi, Department of Pathology, Faculty of Medicine Kuwait University, PO Box 24923 Safat, Kuwait, Code 13110. Tel.: +965 25319476; E-mail: segunade @ yahoo.com.
There is emerging evidence that adipokines are associated with several types of obesity related cancers. Adiponectin is an adipokine that is involved in the 
control of glucose, fat metabolism and insulin sensitivity with anti-diabetic, anti-atherogenic and antiinflammatory activities [1]. In addition to its function as an insulin sensitizing hormone, adiponectin may play a role in the regulation of cell growth and death [2, 3]. It inhibits proliferation of cell through selectively binding and sequestering the growth factors such as Platelet Derived Growth Factor (PDGF), Basic fibroblast growth factor and other factors, thus suppressing their interaction with membrane receptors. Furthermore, adiponectin has been suggested to inhibit the activation of nuclear factor kappa-light-chain-enhancer of activated B cells (NF- $\kappa \mathrm{B})$, a transcription factor that is involved in initiating survival signaling pathway [3]. Adiponectin also promotes apoptosis through activation of a cascade of caspases $-8,-9$ and -3 , which leads to cell death. Hence, it has been proposed that adiponectin is an anti-cancer adipokine that has protective roles against carcinogenesis.

Low levels of adiponectin have been found in a number of obesity related cancers as well as cancers associated with insulin resistance [4] such as breast [5-7], prostate [8] and colon [9]. It has been suggested that reduced levels of adiponectin lead to the development of insulin resistance and compensatory chronic hyperinuslinemia which in turn lead to reduced liver synthesis of IGFBP1 and IGFBP2. As a result levels of bioavailable IGF1 increases favoring the development of tumors. In parallel, chronic hyperinuslinemia down regulates the hepatic synthesis of SHBG, thereby increasing free sex hormones. In addition, low levels of adiponectin may probably up-regulate fatty acid synthase (FAS) a key lipogenic enzyme that has been associated with breast, prostate and colon cancers [10]. A novel signaling pathway linking adiponectin with carcinogenesis is JNK pathway. This belongs to the mammalian mitogen activated protein (MAP) kinase family that acts as a stimulator for different survival signaling pathways including tumor development [11]. Figure 1, summarizes the mechanisms through which obesity related cancers could be mediated.

Screening of the adiponectin encoding gene has led to the discovery of genetic variants and single nucleotide polymorphisms (SNPs) that have been found to be associated with reduced circulating levels of adiponectin, Type 2 diabetes, insulin resistance and obesity [12-14]. Two common SNPs have been studied extensively in the literature the substitution of $\mathrm{T}$ to $\mathrm{G}$ in exon $245 \mathrm{~T}>\mathrm{G}$ (rs2241766) and substitution of $\mathrm{G}$ to $\mathrm{T}$ in intron $2276 \mathrm{G}>\mathrm{T}$ (rs1501299) along with their association with diabetes, obesity and insulin resistance. Data of association analysis of these two previously mentioned SNPs have been inconsistent in different populations. For example, a study in German population has shown significant association of $45 \mathrm{~T}$ $>\mathrm{G}$ variant with obesity and insulin sensitivity [15] whereas a Japanese study found no such association with the same SNP [13].

On the other hand, Hara et al., observed an association between SNPs at positions 45 and 276 and Type 2 diabetes in the Japanese population [12]. Hara and colleagues reported that subjects with the $\mathrm{G} / \mathrm{G}$ genotype at position 45 or the G/G genotype, at position 276 had a significantly increased risk of type 2 diabetes compared with those having the T/T genotype at positions 45 and 276, respectively, indeed more than $40 \%$ of Japanese individuals have the high risk G/G genotype which makes subjects genetically prone to decreased adiponectin levels [12].

In another study, $G$ allele of SNP rs224176 and G/G genotype of SNP rs1501299 were associated with impaired glucose tolerance in Spanish population [16]. The study has also reported that the G/G genotype for SNP rs1501299 was associated with lower serum adiponectin levels compared to $\mathrm{G} / \mathrm{T}$ and $\mathrm{T} / \mathrm{T}$ genotype and hence suggesting that SNP rs1501299 may affect the expression of adiponectin [16]. Reports on the associations of these SNPs have also been inconsistent and, in agreement with reports from Japanese [13] and German [17] populations, the G allele of SNP rs224176 did not result in any change in adiponectin concentrations in the Spanish population [15].

As the associations of these commonly studied polymorphisms in the adiponectin gene with the risk of obesity related cancers have not been established and published data on other associations have been inconsistent, the aims of this study are to (1) investigate the association between adiponectin concentration and other adipokines and breast, prostate and colon cancers, (2) study the influence of polymorphisms in the adiponectin gene on adiponectin levels and potential associations with breast, prostate and colon cancers.

\section{Materials and methods}

\subsection{Patients and controls}

As part of the protocol approved by local ethical committee in accordance with the ethical standards in Helsinki declaration, we obtained fasting blood samples from 132 (66 females, 66 males) cancer patients 


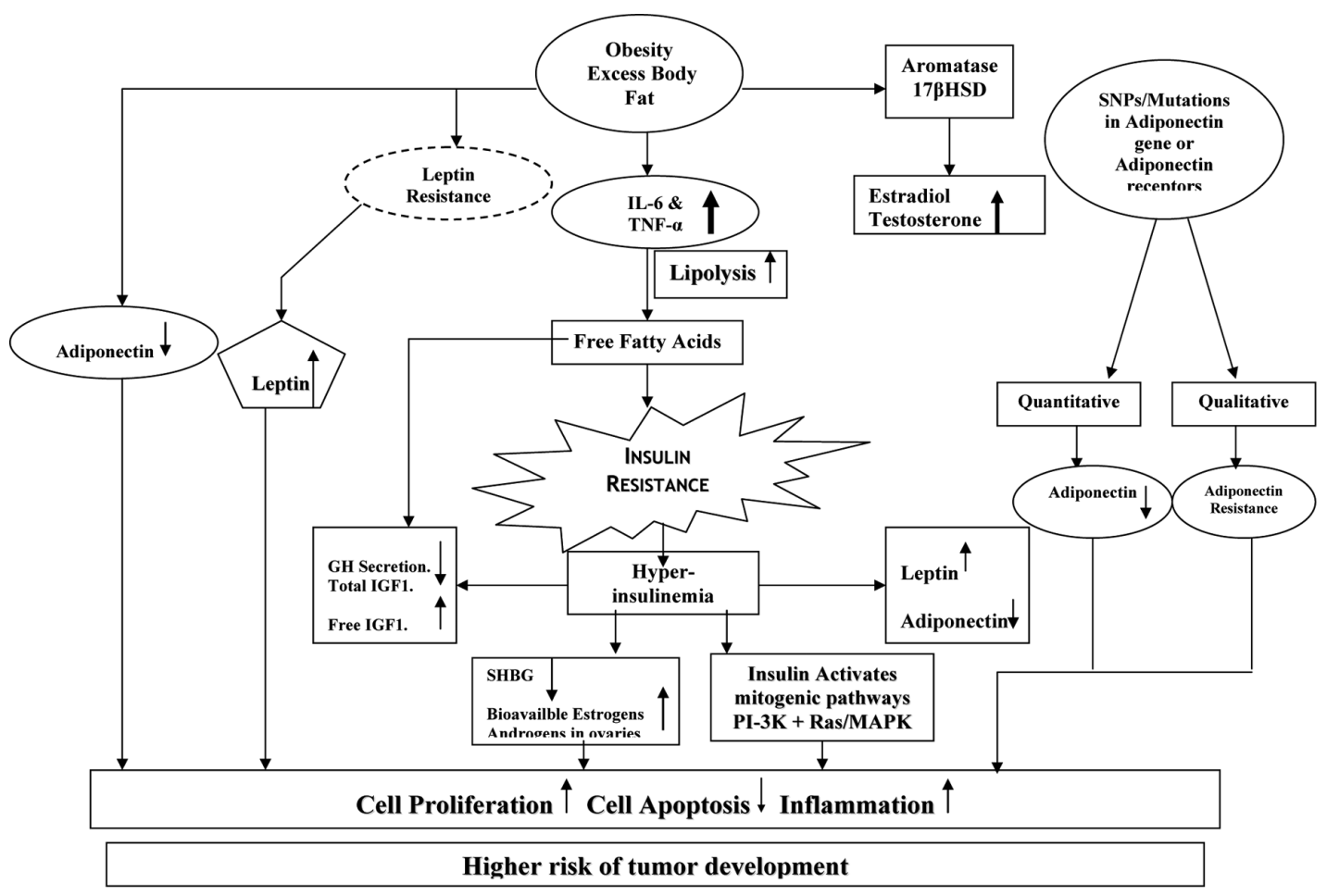

Fig. 1. Mechanisms through which obesity related cancer could be mediated.

who were recruited from Kuwait Cancer Control Center (KCCC). The diagnosis of cancer was made on clinical basis, radiological findings and histological findings. Patients were recruited immediately after diagnosis and before starting treatment. Sixty eight (34 females and 34 males) age and sex matched apparently healthy volunteers were enrolled from Kuwait Blood Bank Center. Exclusion criteria included refusal to participate in the study as well as the presence of other endocrine disease (Diabetes, heart failure, renal failure) or ingestion of any medication (such as thiazolidinedione) that affects adiponectin, hormones or lipid profile at the time of the study. Patients with previous history of other cancers and recent history (within the previous 1-6 months) of weight gain or loss of $5 \%$ or more of their current weight were also excluded from the study.

\subsection{Anthropometric measurements}

Body weight $(\mathrm{Kg})$ was measured in light clothing without shoes and height $(\mathrm{cm})$ was measured with a stadiometer. Subsequently body mass index (BMI) $\left(\mathrm{Kg} / \mathrm{m}^{2}\right)$ was calculated according to the following formula: $\mathrm{BMI}=$ Weight $(\mathrm{Kg}) / \operatorname{Height}\left(\mathrm{m}^{2}\right)$. Waist circumference $(\mathrm{cm})$ at the level of the umbilicus and hip cir- cumference $(\mathrm{cm})$ at the femoral greater trochanter and the maximal gluteal protuberance were also taken. All anthropometric measurements were taken at the time of subject's enrollment and blood draw.

\subsection{Laboratory analysis}

Plasma adiponectin concentrations were measured by Enzyme Linked Immunosorbent Assay (ELISA) Kit (Human Adiponectin ELISA Kit, Linco Research, Missouri, USA). The assay sensitivity is $2 \mathrm{ng} / \mathrm{mL}$. Intra- and Inter assay coefficients of variation were $4 \%$ and $4.1 \%$ respectively at adiponectin concentration of $7 \mu \mathrm{g} / \mathrm{mL}$. Plasma leptin was measured by using the (DSL-1023100 ACTIVE Human Leptin ELISA kit). The assay sensitivity is $0.05 \mathrm{ng} / \mathrm{mL}$, whereas the intra and inter assay coefficients of variation were $3 \%$ and $3.3 \%$ respectively at leptin concentration of $23 \mathrm{ng} / \mathrm{mL}$. Levels of Follicular Stimulating Hormone (FSH), Luteinizing Hormone (LH), Total Testosterone and Sex Hormone Binding Globulin (SHBG) were determined by using IMMULITE 1000 Kits (Siemens Healthcare Diagnostics, Deerfield, USA). Fasting plasma glucose was analyzed on an automated analyzer (Beckman DXC, Beckman Corporation, Brea, CA, USA) and 
Table 1

Demographic, anthropometric and biochemical characteristics of the study population

\begin{tabular}{lccccc}
\hline Parameter & \multicolumn{3}{c}{ Cancer patients $(n=132)$} & Controls $(n=68)$ & $p$-Value \\
\cline { 2 - 4 } Type of Cancer & Breast $(n=60)$ & Prostate $(n=14)$ & Colon $(n=58)$ & & \\
\hline Age (years) & $49 \pm 2.4$ & $59 \pm 8.7$ & $53 \pm 7.7$ & $60 \pm 5.2$ & $\mathrm{NS}$ \\
BMI $(\mathrm{Kg} / \mathrm{m} 2)$ & $28.8 \pm 4.1$ & $27.7 \pm 3$ & $27.9 \pm 6$ & $26.0 \pm 3$ & $\mathrm{NS}$ \\
WC $(\mathrm{cm})$ & $102 \pm 15$ & $108 \pm 14$ & $106 \pm 14$ & $102.5 \pm 9$ & $\mathrm{NS}$ \\
Systolic blood pressure (mmHg) & $131 \pm 20$ & $131 \pm 20$ & $131 \pm 20$ & $130 \pm 12$ & $\mathrm{NS}$ \\
Diastolic blood pressure (mmHg) & $80.6 \pm 6$ & $80.6 \pm 6$ & $80.6 \pm 6$ & $81 \pm 8$ & $\mathrm{NS}$ \\
Plasma glucose (mmol/L) & $6.8 \pm 6$ & $6.8 \pm 2$ & $7.3 \pm 1.7$ & $5.8 \pm 0.5$ & $<0.0001$ \\
Total Cholesterol(mmol/L) & $6 \pm 1$ & $7.1 \pm 2$ & $5.6 \pm 1$ & $6.6 \pm 1.1$ & $\mathrm{NS}$ \\
HDL (mmol/L) & $1.2 \pm 0.5$ & $1.4 \pm 0.9$ & $1.3 \pm 0.4$ & $1.2 \pm 0.07$ & $\mathrm{NS}$ \\
LDL (mmol/L) & $3.9 \pm 2$ & $4.9 \pm 1$ & $3.7 \pm 1$ & $4.4 \pm 0.6$ & $\mathrm{NS}$ \\
Adiponectin $(\mu \mathrm{g} / \mathrm{mL})$ & $8.45 \pm 4$ & $10.4 \pm 3$ & $8.6 \pm 4$ & $4.1 \pm 2$ & $<0.0001$ \\
Insulin $(\mu \mathrm{IU} / \mathrm{mL})$ & $13 \pm 4.8$ & $10.73 \pm 6$ & $10.4 \pm 8.6$ & $11.0 \pm 1.5$ & $<0.0001$ \\
HOMA & $4.3 \pm 0.4$ & $3.4 \pm 0.5$ & $3.3 \pm 0.2$ & $3.0 \pm 0.7$ & $<0.0001$ \\
\hline
\end{tabular}

BMI = Body Mass Index, WC $=$ Waist Circumference, HOMA $=$ Homeostasis Model Assessment.

fasting serum insulin was determined by an enzymelinked immunosorbent assay (ELISA) (DSL-10-1600 ACTIVE, Diagnostics Systems Laboratories, Texas, USA). Homeostasis Model Assessment (HOMA) was used as an assessment for insulin resistance by using the HOMA-IR $=$ glucose $(\mathrm{mmol} / \mathrm{L}) \mathrm{X}$ insulin $(\mu \mathrm{IU} / \mathrm{mL}) / \mathrm{by}$ 22.5 .

\subsection{DNA isolation}

Nucleospin Blood Kit (Macherey-Nagel, NeumannNeader, Germany) was used to extract Deoxyribonucleic acid (DNA) from citrated blood samples, which provided an expected yield range of $4-6 \mu \mathrm{g}$ of DNA. Once DNA was isolated, the DNA quantity and quality were checked using a spectrophotometer.

\subsection{Genotyping of polymorphisms in adiponectin gene}

Allelic Discrimination (AD) of adiponectin gene in 200 samples was done by using 7500 fast Real Time Polymerase Chain Reaction (Applied Biosystems, Foster City, California, USA). SNPs were chosen based on the most commonly reported in the literature and using Applied Biosystems SNP browser version 3.5. Three SNPs were studied as follows: SNP G-10066A (rs182052) in intron 1, SNP 276G $>$ T (rs1501299) in intron 2, SNP 45T $>$ G (rs224176) in exon 2. The selection of the SNPs was based on previous studies showing association with cancer in other population.

\subsection{Statistical analysis}

Data were tested for normality using Kolmogorov Smirnov test. Non-parametric variables were normal- ized by $\log$ transformation to use parametric tests. Descriptive statistics namely mean $\pm \mathrm{SD}$ and $95 \%$ confidence interval (CI) were used as appropriate. Comparison between mean values in the 2 groups ( $\mathrm{Pa}-$ tients and Controls) was evaluated using student's $t$ test. Spearman correlation coefficient was used to describe the associations between continuous variables of interest; the partial correlation analyses were used to control for the effects of age, sex and BMI. The association between adiponectin genotypes and cancer risk was determined by calculating the odds ratio (OR) and 95\% confidence interval (CI) using multivariate and binary logistic regression with adjustment for the confounding effects of age, sex and BMI. The relationship between adiponectin, genotypes and biochemical findings were evaluated by one-way analysis of variance (ANOVA). All the statistical analyses were performed with the Statistical Package for Social Sciences (SPSS Inc. Chicago, USA), version 16.0. The criterion for statistical significance was $p<$ 0.05. Hardy-Weinberg Equilibrium was used to evaluate the allele frequencies using the following facility: www.oege.org/software [18]. The power of the study was calculated using the following facility: http:// hedwig.mgh.harvard.edu/sample_size/size.html [19]. The SPSS software was also used to recode for each combination.

\section{Results}

\subsection{Demographic, anthropometric and biochemical characteristics of the study population}

Table 1 summarizes the demographic, anthropometric and biochemical characteristics of the study popula- 


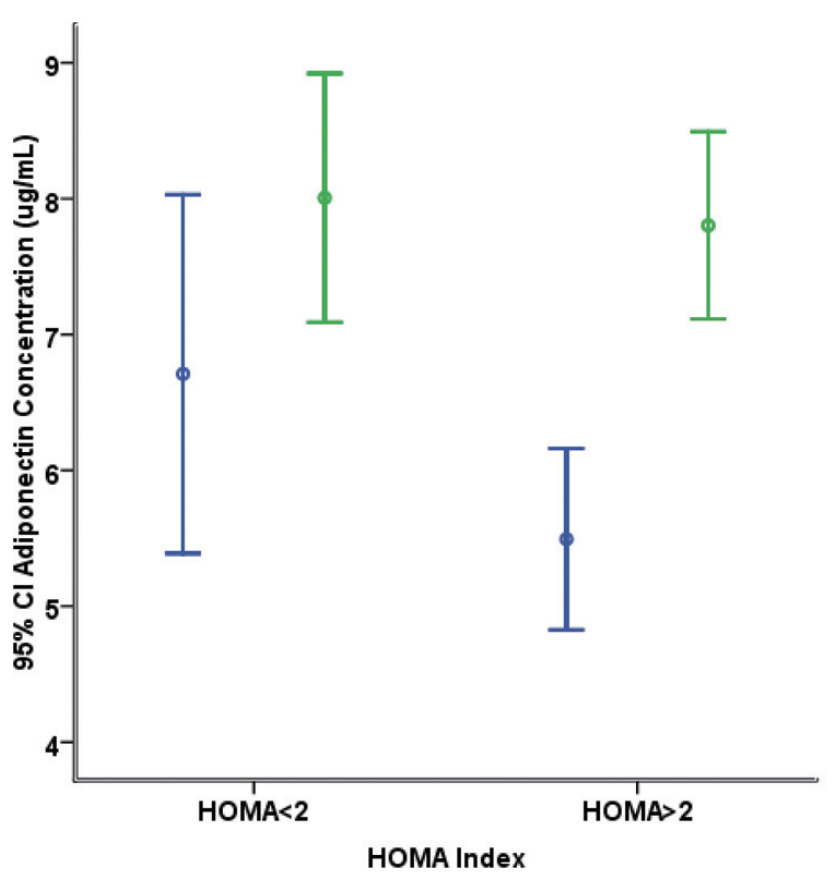

Fig. 2. Differences in adiponectin concentration according to HOMA index. The bars represent the $95 \%$ confidence interval of adiponectin concentration and the circle within the bars represents the mean.

tion. A total of 132 (66 females and 66 males) patients with breast, prostate and colon cancer and 68 (34 females and 34 males) apparently healthy subjects were included in this study.

\subsection{Adiponectin}

Table 2 demonstrates a significant difference in levels of adiponectin in control and patient groups. Cancer patients had significantly $(p<0.0001)$ higher adiponectin concentrations than apparently healthy subjects. Based on BMI and HOMA-sub grouping, levels of adiponectin were lower in obese than in nonobese subjects $(6.9 \pm 4.1 \mu \mathrm{g} / \mathrm{mL}$ vs. $7.9 \mu \mathrm{g} / \mathrm{mL})(p=$ 0.03 ). In addition, insulin sensitive subjects (HOMA $<$ 2) had higher adiponectin levels than insulin resistant subjects (HOMA > 2) (Fig. 2). Adiponectin showed sexual dimorphism in apparently healthy subjects, with female subjects having higher adiponectin levels than male subjects ( $p<0.0001$ ) (Fig. 3). However, Fig. 3 demonstrates that this sexual dimorphism disappeared in cancer patients $(p>0.05)$.

\subsection{Insulin and insulin resistance}

Significant differences in insulin and HOMA were found between patient and control groups; indeed can- cer patients had significantly higher $(p<0.0001)$ insulin levels and significantly higher $(p<0.0001)$ HOMA index as shown in Table 2.

\subsubsection{Stratification of the study population according to the sex}

Table 2 demonstrates the differences between obesity related parameters in control and patient groups of women and men respectively. We found a significant difference in levels of adiponectin in control and patient groups of females and males respectively. Female cancer patients had significantly ( $p=0.03$ ) higher adiponectin concentrations than do apparently healthy subjects. In male cancer patients levels of adiponectin were significantly higher $(p<0.0001)$ than in apparently healthy subjects.

\subsubsection{Insulin and insulin resistance}

Significant differences in insulin and HOMA were found between patient and control groups of females. Female cancer patients had significantly higher $(p<$ $0.0001)$ insulin levels and significantly higher $(p=$ $0.008)$ HOMA index as shown in Table 2. Furthermore, there was a significant difference $(p<0.0001)$ in insulin and HOMA between control and patient groups of males. Males with cancer had significantly higher $(p<0.0001)$ serum insulin levels and subsequently 


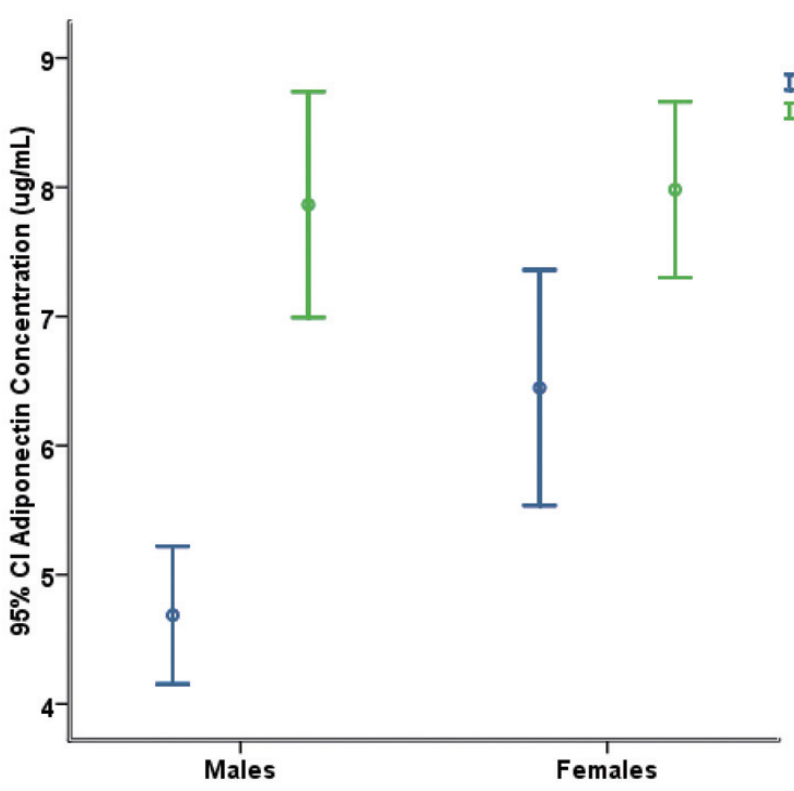

I Apparently healthy

I Cancer Patients

Fig. 3. Sexual Dimorphism of adiponectin in the study subjects. The bars represent the $95 \%$ confidence interval of adiponectin concentration and the circle within the bars represents the mean.

significantly higher HOMA index than do control male subjects (Table 2).

\subsubsection{Hormonal differences between patients and controls}

Female cancer patients had significantly higher $(p<$ $0.0001)$ testosterone levels than do apparently healthy female subjects as shown in Table 2. On the other hand, male cancer patients had significantly higher $(p<$ $0.0001)$ estradiol levels than do male control subjects as appears in Table 2. However, male control subjects had significantly higher $(p<0.0001)$ testosterone levels than do male cancer patients as shown in Table 2 . As shown in Table 2, levels of FSH and LH in female cancer patients were significantly higher $(p<0.0001)$ than female control subjects. Similar trend was observed in male subgroups of patients and controls as shown in Table 2. Although patients groups (females and males) have higher SHBG levels than apparently healthy subjects, the differences were not significant as shown in Table 2.

\subsubsection{Correlation between variables}

Table 3 presents the results of Spearman rank correlations between the variables of interest in all subjects (patients and controls). Insulin levels and HOMA index correlated positively and significantly with BMI and Waist circumference. Adiponectin correlated positive- ly with estradiol but with BMI, waist circumference, insulin, HOMA and total testosterone. Total testosterone correlated positively with waist circumference, insulin levels and HOMA index whereas it correlated negatively with adiponectin and estradiol.

After adjustment for age, sex and BMI, adiponectin correlated positively with estradiol and negatively with insulin levels, HOMA index and testosterone (Table 4) indicating that the correlations between adiponectin and these variables are independent of age, sex and BMI.

\subsubsection{Prevalence rates of adiponectin genotypes in the study population}

Table 5 summarizes the prevalence rates of adiponectin genotypes which were in Hardy- Weinberg equilibrium among the study population.

\subsubsection{Anthropometric and biochemical characteristics according to adiponectin genotypes}

Although no significant difference $(p>0.05)$ was observed in BMI among adiponectin genotypes of SNP rs182052, homozygous carriers of G/G allele had the highest BMI $\left(30 \pm 7.4 \mathrm{Kg} / \mathrm{m}^{2}\right)$ followed by A/A genotypes $\left(29.8 \pm 5 \mathrm{Kg} / \mathrm{m}^{2}\right)$ and $\mathrm{A} / \mathrm{G}$ genotypes $(25.6 \pm$ $5.8 \mathrm{Kg} / \mathrm{m}^{2}$ ). In contrast, the highest waist circumference was found in homozygous carriers of A/A geno- 
Table 3

Spearman's rank correlations of variables of interest among all subjects

\begin{tabular}{|c|c|c|c|c|c|c|c|c|c|}
\hline & & AGE & BMI & WC & INS & HOMA & ADIPO & E2 & TES \\
\hline AGE & $\mathrm{r}$ & 1 & & & & & & & \\
\hline BMI & $r$ & 0.05 & 1 & & & & & & \\
\hline WC & $\mathrm{r}$ & $0.2^{* * *}$ & $0.5^{* * * *}$ & 1 & & & & & \\
\hline INS & $\mathrm{r}$ & 0.06 & $0.3^{* * * *}$ & $0.3^{* * * *}$ & 1 & & & & \\
\hline HOMA & $\mathrm{r}$ & 0.07 & 0.3 & 0.3 & $0.9^{* * * *}$ & 1 & & & \\
\hline ADIPO & $r$ & $-0.1^{*}$ & $-0.1^{*}$ & $-0.2^{* *}$ & $-0.2^{* * * *}$ & $-0.2^{* * * *}$ & 1 & & \\
\hline E2 & $\mathrm{r}$ & 0.08 & -0.07 & 0.02 & -0.2 & -0.2 & 0.2 & 1 & \\
\hline TES & $\mathrm{r}$ & 0.09 & -0.03 & 0.1 & $0.2^{* * * *}$ & $0.1^{* *}$ & $-0.2^{* *}$ & $-0.2^{* *}$ & 1 \\
\hline
\end{tabular}

Table 4

Partial correlation coefficients among subjects after correction for age, sex and BMI

\begin{tabular}{|c|c|c|c|c|c|c|c|}
\hline & & $\mathrm{WC}$ & INS & HOMA & ADIPO & E2 & TES \\
\hline WC & $\mathrm{r}$ & 1 & & & & & \\
\hline INS & $\mathrm{r}$ & 0.2 & 1 & & & & \\
\hline HOMA & $\mathrm{r}$ & 0.2 & $0.9^{* * * *}$ & 1 & & & \\
\hline ADIPO & $\mathrm{r}$ & 0.08 & $-0.3^{*}$ & $-0.3^{*}$ & 1 & & \\
\hline E2 & $\mathrm{r}$ & 0.08 & -0.1 & -0.08 & $0.3^{* * * *}$ & 1 & \\
\hline TES & $\mathrm{r}$ & 0.04 & 0.03 & -0.01 & $-0.4^{* * * *}$ & $-0.2^{*}$ & 1 \\
\hline \multicolumn{8}{|c|}{$\begin{array}{l}{ }^{*} p<0.05,{ }^{* *} p<0.01,{ }^{* * *} p<0.001,{ }^{* * * *} p<0.0001, \text { No }{ }^{*}=\text { No } \\
\text { Significance. } \\
\text { Age }=\text { years, BMI = Body Mass Index }(\mathrm{Kg} / \mathrm{m} 2), \text { WC }=\text { Waist Circum- } \\
\text { ference }(\mathrm{cm}), \mathrm{INS}=\text { Insulin }(\mu \mathrm{IU} / \mathrm{mL}), \mathrm{HOMA}=\text { Homeostasis Model As- } \\
\text { sessment, ADIPO = Adiponectin }(\mu \mathrm{g} / \mathrm{mL}), \mathrm{E} 2=\text { Estradiol }(\mathrm{pg} / \mathrm{mL}), \text { TES } \\
=\text { Testosterone }(\mathrm{ng} / \mathrm{dL}) .\end{array}$} \\
\hline
\end{tabular}

types $(104.2 \pm 14.2 \mathrm{~cm})$ of SNP rs182052, followed by $\mathrm{G} / \mathrm{G}(103.1 \pm 16.2 \mathrm{~cm})$ and $\mathrm{A} / \mathrm{G}$ genotypes $(101.9 \pm$ $12.6 \mathrm{~cm})$. However, the differences did not reach statistical significance $(p>0.05)$. There was also no significant difference in BMI and waist circumference between the SNP rs1501299 and SNP rs2241766 genotypes indicating that variations in anthropometric indices are not related to genetic polymorphisms in the adiponectin gene.

\subsubsection{Variation of adiponectin and other obesity related parameters with adiponectin genotypes in both patients and controls}

There were significant differences in adiponectin levels in SNP rs1501299 genotypes (Table 6). Table 6 shows that homozygous carriers of $\mathrm{T}$ allele $(\mathrm{T} / \mathrm{T})$ had the lowest concentration of adiponectin compared to the $\mathrm{G} / \mathrm{G}$ or $\mathrm{T} / \mathrm{G}$ genotypes. Insulin levels and HOMA index also varied significantly among SNP rs1501299 genotypes as shown in Table 6. Although leptin levels varied among genotypes of SNP rs1501299, the differences were not significant.
Homozygous carriers of the $G$ allele of SNP rs182052 tended to have lower adiponectin levels than carriers of $(\mathrm{A} / \mathrm{A})$ or $(\mathrm{A} / \mathrm{G})$ genotypes $[(\mathrm{G} / \mathrm{G}: 4.7 \pm$ $2 \mu \mathrm{g} / \mathrm{mL}, \mathrm{A} / \mathrm{A}: 5.5 \pm 3 \mu \mathrm{g} / \mathrm{mL}, \mathrm{A} / \mathrm{G}: 6.9 \pm 3.7 \mu \mathrm{g} / \mathrm{mL})]$ but this differences were not significant. Among the genotypes of SNP rs2241766, homozygous carriers of the $\mathrm{G}$ alleles had the highest levels of adiponectin compared with the other genotypes as follows: [ $(\mathrm{G} / \mathrm{G}$ : $7.7 \pm 1.8 \mu \mathrm{g} / \mathrm{mL}, \mathrm{T} / \mathrm{T}: 6.8 \pm 4.1 \mu \mathrm{g} / \mathrm{mL}, \mathrm{G} / \mathrm{T}: 6.6 \pm$ $4.1 \mu \mathrm{g} / \mathrm{mL})]$. Although variations in insulin, leptin and other variables were observed among genotypes of SNP rs182052 and SNP rs2241766, the differences were not statistically significant, hence, data not shown.

\subsubsection{Adiponectin genotypes and multivariate linear regression results:}

Using multivariate logistic regression analysis with inclusion of age and sex as confounders, we found that (GG) genotype of SNP rs1501299 was significantly associated with levels of adiponectin ( $\mathrm{B}=0.2, p=$ 0.013 ) as shown in Table 7. Also homozygous carriers of $\mathrm{G}$ allele are more likely to have higher adiponectin levels than $(\mathrm{T} / \mathrm{T})$ or $(\mathrm{T} / \mathrm{G})$ genotypes of SNP rs1501299 
Table 5

The distribution of adiponectin genotypes within the study population

\begin{tabular}{lcc}
\hline Adiponectin genotype & Number of controls $(n=68)$ & Number of patients $(n=132)$ \\
\hline SNP rs182052 & \\
AA & $4(5.9 \%)$ & $8(6.1 \%)$ \\
AG & $52(76.5 \%)$ & $101(76.5 \%)$ \\
GG & $12(17.6 \%)$ & $23(17.4 \%)$ \\
SNP rs1501299 & \\
TT & $46(67.6 \%)$ & $63(47.73 \%)$ \\
GT & $21(30.9 \%)$ & $55(41.67 \%)$ \\
GG & $1(1.5 \%)$ & $14(10.61 \%)$ \\
SNP rs2241766 & & \\
TT & $50(73.5 \%)$ & $84(63.64 \%)$ \\
TG & $18(26.5 \%)$ & $43(32.58 \%)$ \\
GG & None & $5(3.79 \%)$ \\
TOTAL & $68(100 \%)$ & $132(100 \%)$ \\
\hline
\end{tabular}

* Significant Difference in the distribution of GG genotype between controls and patients.

$(\mathrm{OR}=1.2,95 \% \mathrm{CI}(1.0-1.3), p=0.02)$. We also found that this genotype is associated with lower insulin levels $(\mathrm{OR}=0.8,95 \% \mathrm{CI}(0.8-0.9), p=0.03)$. But this genotype was not found to be associated with any parameters of obesity (BMI or waist circumference). SNP rs2241766 and SNP rs182052 genotypes were not found to be associated with indices of obesity, insulin resistance and adiponectin (Table 7). Using binary logistic regression analysis with inclusion of age and sex as confounders, SNP rs1501299 was significantly associated with cancer in all patients $(\mathrm{OR}=2.195 \% \mathrm{CI}$ (1.3-3.6), $p=0.004$ ) as shown in Table 8. Specifically GG genotype was strongly associated with cancer development $(\mathrm{OR}=9.3,95 \% \mathrm{CI}(1.2-73, p=0.04)$ in all patients. It is also associated with the development of breast cancer $(\mathrm{OR}=8.5,95 \% \mathrm{CI}(1.03-71), p=0.04)$ and colon cancer $(\mathrm{OR}=12.0,95 \% \mathrm{CI}(1.2-115), p=$ $0.03)$. SNP rs2241766 was associated with breast can$\operatorname{cer}(\mathrm{OR}=2.1,95 \% \mathrm{CI}(1.1-4.1), p=0.03)$ but not with prostate and colon cancers. We have corrected for confounders such as age, BMI and gender, as we also included adiponectin as a confounder, results did not differ indicating that the association between adiponectin SNPs with obesity related cancers is independent of age and sex. However, Table 8 shows that the association between GG genotype of SNP rs1501299 and breast cancer is dependent on age, adiponectin levels, BMI, and sex.

\section{Discussion}

Several published studies have shown an association between obesity and risk of developing prostate, breast and colon cancers [20-22]. Additionally, there has been evidence that the link between obesity and risk of cancer is due, in part, to obesity-associated reduction in circulating adiponectin levels [23]. To the best of our knowledge most of the studies have shown that cancer patients had lower adiponectin levels compared to their apparently healthy control subjects. Mantzores and colleagues, have shown that lower circulating adiponectin levels are associated with increased risk of breast cancer [5,6] Furthermore, adiponectin levels have been demonstrated to be lower in prostate cancer patients compared to benign prostatic hyperplasia or healthy control subjects and inversely associated with histological grade and Gleason score [24]. On the other hand, Biallargeon et al., found no association between adipokines, adiponectin in particular and prostate cancer [25]. One prospective nested case control study reported that plasma adiponectin levels were inversely associated with the risk of colorectal cancer in men [9].

Findings in this study came as a surprise because we were expecting to find lower adiponectin in association with obesity related cancers as reported in studies from other populations mentioned earlier. Therefore, our findings of significantly higher adiponectin in patients with cancer are at variance with other published studies. Our results could be explained by a number of factors. First of all it is pertinent to note that the associations of adiponectin with obesity and obesity related factors such as insulin resistance are in agreement with what is expected from published studies. For example, adiponectin was inversely correlated with markers of obesity BMI and waist circumference as shown in Tables 3 and 4. Adiponectin also showed the expected significant inverse relationships with insulin resistance and insulin levels as shown in Tables 3 and 4. Based on HOMA sub-grouping, insulin sensitive sub- 
jects $(\mathrm{HOMA}<2)$ had higher adiponectin levels than insulin resistant subjects (HOMA $>2$ ) as shown in Fig. 2.

The higher levels of adiponectin in cancer patient groups could be due to slightly lower (but significant) waist circumference in the patient group particularly in male cancer patients as shown in Table 2. Circulating adiponectin in this study has been shown to be negatively correlated more significantly with waist circumference than BMI in agreement with other previous studies [26,27]. As estradiol correlated positively with adiponectin, another important factor that could explain the high levels of adiponectin in male cancer patients is the significantly lower testosterone and relatively higher estradiol levels which in turn could result in increased production of adiponectin in male cancer patients. In relation to sex steroids, the findings in females are difficult to explain, female cancer patients had significantly higher testosterone levels which is expected to result in lower adiponectin levels due to the fact that testosterone suppresses adiponectin production and also limits the production of HWM adiponectin in vivo and in cultured adipocytes [28-30]. However, there is the possibility that the effect of testosterone on adiponectin is different in males and females. More significantly, females with cancer had higher estradiol due to their higher BMI which could result in higher rate of peripheral aromatization. Thus, it is highly probable that the effect of estradiol on increasing circulating adiponectin overrides a tendency of higher testosterone to reduce adiponectin. Obviously, sex steroids play a role in regulation of adiponectin levels and the regulation could differ in men and women.

Discrepancies between our results and previous studies could also be explained by ethnic/racial differences; indeed previous studies were conducted on populations from USA, Europe and Japan. Genetic studies have associated several adiponectin gene polymorphisms with adiponectin levels, obesity, insulin resistance, Type 2diabetes, hypertension and cardiovascular diseases in some but not all studies [12-14]. In this study we have found that SNP $276 \mathrm{G}>\mathrm{T}$ was significantly associated with cancer in all patients while SNP rs2241766 was associated with breast cancer but not with prostate and colon cancers. Furthermore, in contrast with what has been reported in other populations, the (GG) genotype of rs1501299 was significantly associated with higher levels of adiponectin and rs2241766 and SNP rs182052 genotypes were not found to be associated with adiponectin, indices of obesity and insulin resistance. All the SNPs evaluated in this study were not significantly associated with indices of obesity in sharp contrast to reports from other populations. A study in Hispanic families reported that SNP rs182052 was associated with four of six obesity measurements (BMI, Waist, WHR, subcutaneous fat) [17] and Yang et al., (2007) reported that G allele of SNP rs1501299 was associated with reduced risk of obesity [32]. In addition, SNP rs2241766, either independently [31] or as a haplotype together with SNP rs1501299 [15], was strongly associated with obesity and insulin resistance in nondiabetic German and Italian Caucasians. However, there are inconsistent results from various populations as these associations were not found in French [14] and Swedish [34] populations suggesting high variability in phenotypic expression among different populations. The lack of significant association between the studied SNPs and indices of obesity is reflected in their lack of significant associations with leptin (Table 6).

In this study, the differences in circulating adiponectin between genotypes of SNP rs182052 were not statistically significant. This may be explained by the fact that SNP rs182052 is an intronic SNP that may not affect the protein product of adiponectin gene. However, we have also found that the G/G genotype of SNP rs1501299 resulted in higher serum adiponectin levels. Our findings are in contrast with results reported in Japanese and Spanish populations that showed lower adiponectin levels in $\mathrm{G}$ allele carriers of SNP rs1501299 [13,14]. The mechanism by which the intronic SNP rs1501299 can affect the expression level of the gene and increase circulating adiponectin could be explained by several factors. It might be due to a specific linkage structure or it may act with certain environmental factors and ultimately affect the expression of the gene (gene-environmental interaction). One study has indicated that SNP rs1501299 is in moderate to strong Linkage Disequilibrium with several polymorphisms such as insertion/deletion +2019 placed in the 3 un-translated region (UTR) - a region which has been shown to play a role in the control of gene expression by binding proteins that regulate mRNA processing, translation or degradation [33]. On the other hand, we showed that neither T nor G alleles of SNP rs2241766 resulted in any change in adiponectin concentrations. As SNP rs2241766 is a silent substitution (GGT $\rightarrow$ GGG), it may indicate that this variant does not affect the expression of the gene. Our findings agree with reports from Japanese and German populations [11,28] which found no association between SNP rs2241766 and adiponectin but at variance with Menzaghi et al., who showed association of insulin resistance with the 
T allele with decreased serum adiponectin levels [37]. The conflicting association results in various populations suggest a complex relationship between variations in the adiponectin gene and phenotypic adiponectin levels. This could explain the difference between our study and that of Kaklamani et al., who found increased breast cancer risk in adiponectin gene SNPS that are associated with lower adiponectin levels and decreased risk of cancer with SNPs that increase adiponectin levels [37]. In this study we found a significant association between SNP rs1501299 and cancer in all patients, breast, and colon cancer as shown in Table 8 . Our finding of an association between an adiponetin gene SNP that causes higher adiponectin and cancer deserves further prospective association studies. It is unlikely that cancer-related weight loss could be a factor in our patients since none of the patients reported significant weight loss. The study by Kaklamani et al., was retrospective and did not include data on the BMI as well as other obesity-related metabolic parameters that could interfere with the genotype effect [37].

Discrepancies between our study and other association studies could also be explained by ethnic/racial differences and it is possible that certain alleles actually have different functions in different populations. Furthermore, different SNPs in adiponectin gene can give rise to more than one allelic messenger ribose nucleic acid (mRNA) forms which in turn possess different biological functions as a result of differences in primary or higher order structures that interact with other cellular components [38]. The recent finding of increased levels of tissue adiponectin in breast cancer patients compared to controls gives further support to our finding of an association between an SNP that causes higher adiponectin levels and cancer [39]. The study by Karaduman et al., also reported that, women with high levels of tissue adiponectin are at increased risk of developing breast cancer than women with low tissue adiponectin levels [39]. Another recent study has reported that serum adiponectin levels were higher in advanced than organ confined prostate cancer [40]. This study also reported that adiponectin could be used as a tumor marker to differentiate between advanced and localized stages of prostate cancer [40]. It is highly probable that patients with advanced stages of cancer could have higher circulating adiponectin especially if the cancer cells produce adiponectin. However there are no studies that have evaluated tissue expression of adiponectin in relation to circulating adiponectin levels and no studies have evaluated adiponectin production from tumor cells as a potential tumor marker. If con- firmed by other studies, there could be a paradigm shift in the belief that adiponectin SNPs that cause higher adiponectin levels are associated with decreased risk of cancer.

There are some limitations to this study. Although the number of study subjects gives the study a statistical power of $90 \%$ to detect the changes in adiponectin levels, the number of subjects with certain genotypes is small and studies in larger populations are required to confirm our findings. The assay used in this study identifies total adiponectin and cannot distinguish between the adiponectin isoforms, high- and low-molecularweight complexes which may have different biological activities. Studies have also shown that posttranslational modifications such as glycosylation at lysine residues located in the collagenous domain of adiponectin are major determinants of the biological activity of adiponectin [41,42].

In conclusion, several adiponectin polymorphisms have been shown to influence adiponectin levels [1214]. To date, few studies explored the association of adiponectin polymorphisms with obesity related cancers. Our study has shown that the genetic polymorphism SNP rs1501299 is an important genetic regulator that results in increased adiponectin levels and, paradoxically, may be the predisposing factor in these patients. Further studies will be necessary to confirm the role of SNP rs1501299 and SNP rs2241766 in the development of obesity related cancers.

\section{Acknowledgment}

The financial support received from the College of Graduate Studies (Research Administration grant YM11/07) and Kuwait Foundation for the Advancement of Science grant number (2006-1302-05) is acknowledged. We acknowledge contribution of the General Facility KU Project (GM01/05).

\section{Conflict of Interest}

No conflict of interest.

\section{Genes discussed}

Adiponectin- encoding gene: ADIPOQ Or ACDC 


\section{References}

[1] T. Kadowaki and T. Yamauchi, Adiponectin and Adiponectin Receptors, Endoc Rev 26 (2005), 439-451.

[2] E. Brakenhielm, N. Veitonmäki, R. Cao, S. Kihara, Y. Matsuzawa, B. Zhivotovsky, T. Funahashi and Y. Cao, Adiponectin-induced antiangiogenesis and antitumor activity involve caspase-mediated endothelial cell apoptosis, PNAS $\mathbf{1 0 1}$ (2004), 2476-2248.

[3] Y. Wang, K. Lam, J. Xu, G. Lu, L.Y. Xu, G.J. Cooper and A. $\mathrm{Xu}$, Adiponectin inhibits cell proliferation by interacting with several growth factors in an oligomerization-dependent manner, J Biol Chem 280 (2005), 18341-18347.

[4] A. Wolk, G. Gridley, M. Svensson, O. Nyrén, J.K. McLaughlin, J.F. Fraumeni and H.O. Adam, A prospective study of obesity and cancer risk (Sweden), Cancer Cause Control 12 (2001), 13-21.

[5] C. Mantzoros, E. Petridou, N. Dessypris, C. Chavelas, M. Dalamaga, D.M. Alexe, Y. Papadiamantis, C. Markopoulos, E. Spanos, G. Chrousos, D. Trichopoulos et al., Adiponectin and breast cancer risk, J Clin Endocrinol Metab 89 (2004), 1102-1107.

[6] Y. Miyoshi, T. Funahashi, S. Kihara, T. Taguchi, Y. Tamaki, Y. Matsuzawa and S. Noguchi, Association of serum adiponectin levels with breast cancer risk, Clin Cancer Res 9 (2003), 56995704.

[7] D. Chen, Y. Chung, Y. Yeh, H.C. Chaung, F.C. Kuo, O.Y. Fu, H.Y. Chen, M.F. Hou and S.S. Yuan, Serum adiponectin and leptin levels in Taiwanese breast cancer patients, Cancer Lett (in press), Cancer Lett 237 (2006), 109-114.

[8] K. Michalakis, C.J. Williams, N. Mitsiades, J. Blakeman, S. Balafouta-Tselenis, A. Giannopoulos and C.S. Mantzoros, Serum adiponectin concentrations and tissue expression of adiponectin are reduced in patients with prostate cancer: a case-control study, Cancer Epidemiol Biomarkers Prev 16 (2007), 308-313.

[9] E. Wei, E. Giovannucci, C. Fuchs, W.C. Willett and C.S. Mantzoros, Low Plasma Adiponectin Levels and Risk of Colorectal Cancer in Men: A Prospective Study, JNCI 97 (2005), 1688-1694.

[10] Z. Luo, A. Saha, X. Xiang and N. Ruderman, AMPK, the metabolic syndrome and cancer, Trends Pharmacol Sci 26 (2005), 69-76.

[11] R. Davis, Signal transduction by the JNK group of MAP kinases, Cell 103 (2000), 239-252.

[12] K. Hara, P. Boutin, Y. Mori, K. Tobe, C. Dina, K. Yasuda, T. Yamauchi, S. Otabe, T. Okada, K. Eto, H. Kadowaki, R. Hagura et al., Genetic variation in the gene encoding adiponectin is associated with an increased risk of type 2 diabetes in the Japanese population, Diabetes 51 (2002), 536-540.

[13] M. Takahashi, Y. Arita, K. Yamagata, Y. Matsukawa, K. Okutomi, M. Horie, I. Shimomura, K. Hotta, H. Kuriyama, S. Kihara, T. Nakamura, S. Yamashita et al., Genomic structure and mutations in adipose-specific gene, adiponectin, Int J Obes $\mathbf{2 4}$ (2000), 861-868.

[14] F. Vasseur, N. Helbecque, C. Dina, S. Lobbens, V. Delannoy, S. Gaget, P. Boutin, M. Vaxillaire, F. Leprêtre, S. Dupont, K. Hara, K. Clément et al., Single nucleotide polymorphism haplotypes in the both proximal promoter and exon 3 of the APM1 gene modulate adipocyte-secreted adiponectin hormone levels and contribute to the genetic risk for type 2 diabetes in French Caucasians, Hum Mol Gen 11 (2002), 2607-2614.

[15] M. Stumvoll, O. Tschritter, A. Fritsche, H. Staiger, W. Renn, M. Weisser, F. Machicao and H. Häring, Association of the
T-G polymorphism in adiponectin (exon 2) with obesity and insulin sensitivity: interaction with family history of type 2 diabetes, Diabetes 51 (2002), 37-41.

[16] J. Gonzalez Sanchez, C. Zabena, Martinez-Larrad, C. Fernandez Perez, M. Perez Barba, M. Laakso and Manuel Serrano Rio, An SNP in the adiponectin gene is associated with decreased serum adiponectin levels and risk for impaired glucose tolerance, Ob Res 13 (2005), 807-812.

[17] A. Schaffler, N. Barth, K.D. Palitzsch, W. Drobnik, J. Schölmerich and G. Schmitz, Mutation analysis of the human adipocyte specific apM-1 gene, Eur J Clin Invest 30 (2000), 879-887.

[18] www.oege.org/software accessed January - March 2009.

[19] http://hedwig.mgh.harvard.edu/sample_size/size.html. Accessed December 2008.

[20] E. Calle, C. Rodriguez, K. Walker-Thurmond and M. Thun, Overweight, obesity, and mortality from cancer in a prospectively studied cohort of U. S. adults, N Engl J Med 348 (2003), 1625-1638.

[21] IARC handbooks of cancer prevention, Weight control and physical activity, Vol 6, International Agency for Research on Cancer, Lyon, France, 2002.

[22] Kumar, Abbas, Fausto, Robbins and Cotran Pathologic Basis of Disease, (7th ed.), Philadelphia, United States of America: Elsevier Saunders, 2005.

[23] D. Barb, C. Williams, A. Neuwirth and C.S. Mantzoros, Adiponectin in relation to malignancies: a review of existing basic research and clinical evidence, Am J Clin Nutr 87 (2007), 858S-866S.

[24] S. Goktas, M.I. Yilmaz, K. Caglar, A. Sonmez, S. Kilic and S. Bedir, Prostate cancer and adiponectin, Urol 65 (2005), 1168-1172.

[25] J. Baillargeon and D.P. Rose, Obesity, adipokines, and prostate cancer, Int J Oncol 28 (2006), 737-745.

[26] J. Smith, M. Al-Amri, A. Sniderman and K. Cianflone, Leptin and adiponectin in relation to body fat percentage, waist to hip ratio and the apoB/apoA1 ratio in Asian Indian and Caucasian men and women, Nutr and Metab (Lond) 3 (2006), 18-26.

[27] Y. Arita, S. Kihara, N. Ouchi, M. Takahashi, K. Maeda, J. Miyagawa, K. Hotta, I. Shimomura, T. Nakamura, K. Miyaoka, H. Kuriyama, M. Nishida, S. Yamashita, K. Okubo, K. Matsubara, M. Muraguchi, Y. Ohmoto, T. Funahashi and Y. Matsuzawa, Paradoxical decrease of an adipose-specific protein, adiponectin, in obesity, Biochem Biophys Res Commun 257 (1999), 79-83.

[28] T. Combs, A. Berg, M. Rajala, S. Klebanov, P. Iyengar, J. Jiminiz-Chillaron, M.E. Patti, S.L. Klein, R.S. Weinstein and P.E. Scherer, Sexual differentiation, pregnancy, caloric restriction and aging affect the adipocyte specific secretory protein adiponectin, Diabetes 52 (2003), 268-276.

[29] H. Nishizawa, I. Shimomura, K. Kishida, N. Maeda, H. Kuriyama, H. Nagaretani, M. Matsuda, H. Kondo, N. Furuyama, S. Kihara, T. Nakamura, Y. Tochino et al., Androgens decrease plasma adiponectin, an insulin sensitizing adipocyte derived protein, Diabetes 51 (2002), 2734-2741.

[30] A. Xu, K. Chan, R. Hoo, Y. Wang, K. Tan, J. Zhang, B. Chen, M. Lam, C. Tse, G. Cooper and K. Lam, Testosterone selectively reduces the high molecular weight form of adiponectin by inhibiting its secretion from adipocytes, J Biol Chem $\mathbf{2 8 0}$ (2005), 18073-18080.

[31] W. Yang, Y. Yang, C. Chen, I.L. Wu, J.Y. Lu, F.H. Lu, T.Y. Tai and C.J. Chang, Adiponectin SNP276 is associated with obesity, the metabolic syndrome, and diabetes in the elderly, Am J Clin Nutr 2 (2007), 274-275. 
[32] B.S.Sutton, S. Weinert, C.D. Langefeld, A.H. Williams, J.K. Campbell, M.F. Saad, S.M. Haffner, J.M. Norris and D.W. Bowden, Genetic analysis of adiponectin and obesity in Hispanic families: the IRAS Family Study, Hum Gen 117 (2005), 107-118.

[33] C. Menzaghi, V. Trischitta and A. Doria, Genetic Influences of adiponectin on insulin resistance, type 2 diabetes and cardiovascular disease, Diabetes 56 (2007), 1198-1209.

[34] O. Ukkola, E. Ravussin, P. Jacobson, L. Sjöström and C. Bouchard, Mutations in the adiponectin gene in lean and obese subjects from the Swedish obese subjects cohort, Metabolism 52 (2003), 881-884.

[35] H.F. Gu, A. Abulaiti, C.G. Ostenson, K. Humphreys, C. Wahlestedt, A.J. Brookes and S. Efendic, Single nucleotide polymorphisms in the proximal promoter region of the adiponectin (APM1) gene are associated with type 2 diabetes in Swedish caucasians, Diabetes 53 (2004), S31-S35.

[36] C. Menzaghi, T. Ercolino, R. Di Paola, A.H. Berg, J.H. Warram, P.E. Scherer, V. Trischitta and A. Doria, A haplotype at the adiponectin locus is associated with obesity and other features of the insulin resistance syndrome, Diabetes 51 (2002), 2306-2312.

[37] V. Kaklamani, M. Sadim, A. Hsi, K. Offit, C. Oddoux, H.
Ostrer, H. Ahsan, B. Pasche and C. Mantzoros, Variants of the adiponectin gene and adiponectin receptor 1 genes and breast cancer risk, Cancer Res 68 (2008), 3178-3184.

[38] L.X. Shen, J.P. Basilion and V.P. Stanton Jr., Single-nucleotide polymorphisms can cause different structural folds of mRNA, PNAS 96 (1999), 7871-7876.

[39] M. Karaduman, A. Bilici, A. Ozet, A. Sengul, U. Musabak and M. Alomeroglu, Tissue levels of adiponectin in breast cancer patients, Med Oncol 24 (2007), 361-366.

[40] D. Housa, Z. Vernerová, J. Heráèek, B. Procházka, P. Èechák, J. Kuncová and M. Haluzík, Adiponectin as a Potential Marker of Prostate Cancer Progression: Studies in Organ-Confined and Locally Advanced Prostate Cancer, Physio Res 57 (2008), 451-458.

[41] U. Pajvani, X. Du, T. Combs, A. Berg, M. Rajala, T. Schulthess, J. Engel, M. Brownlee and P. Scherer, Structurefunction studies of the adipocyte-secreted hormone Acrp30/ adiponectin. Implications for metabolic regulation and bioactivity, J Biol Chem 278 (2003), 9073-9085.

[42] T. Taso, H.F. Lodish and J. Fruebis, ACRP30, a new hormone controlling fat and glucose metabolism, Eur J Pharmacol 440 (2002), 213-221. 


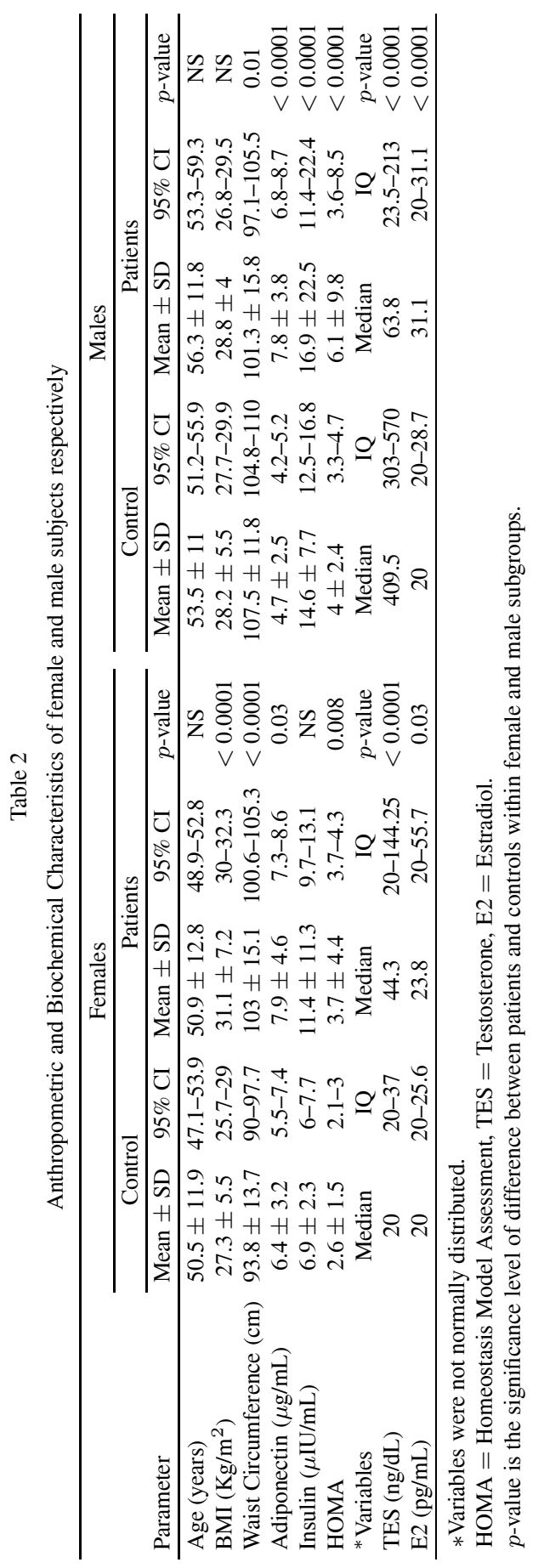




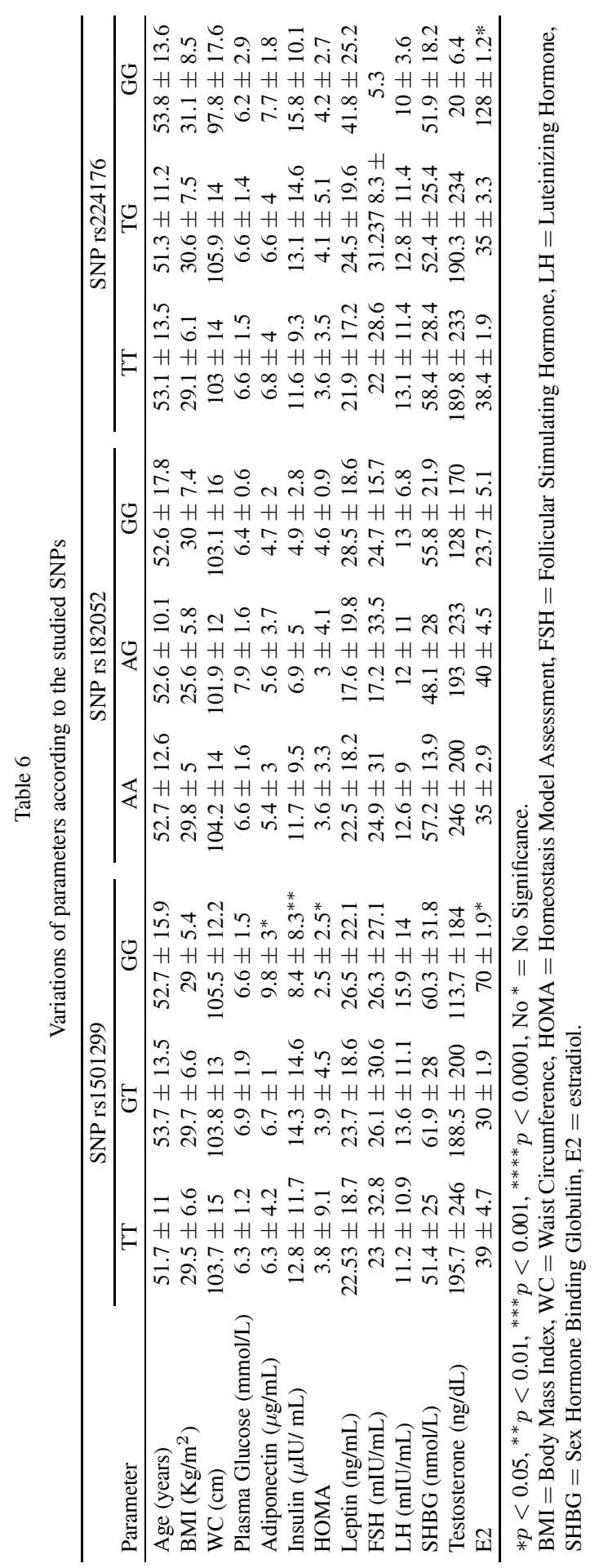




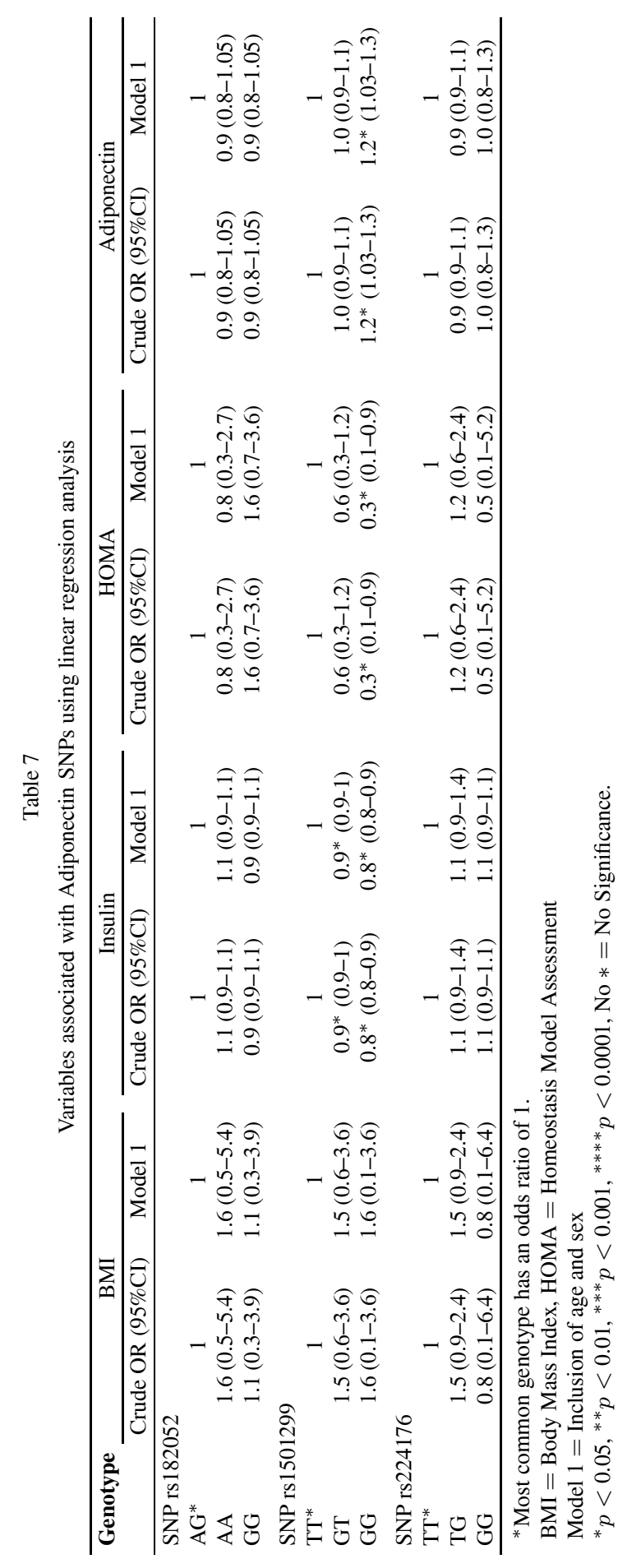




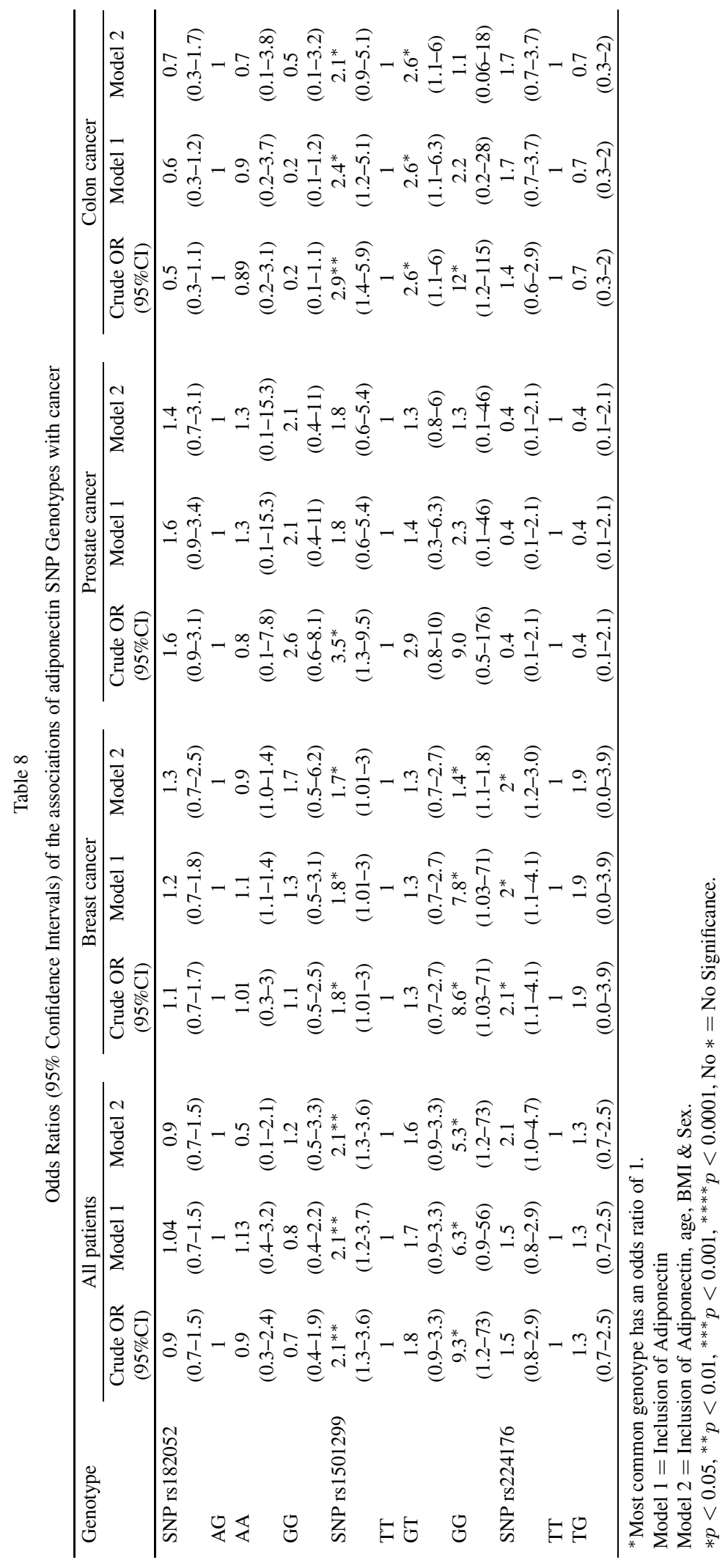




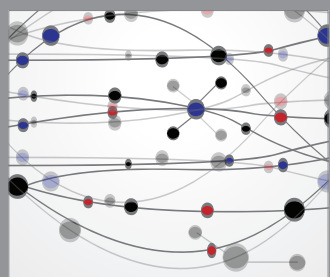

The Scientific World Journal
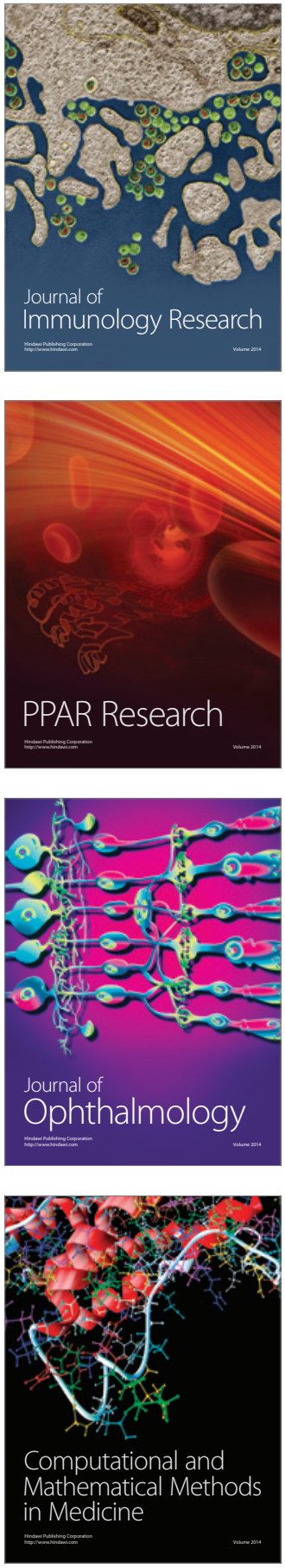

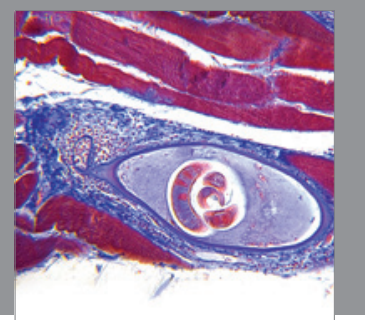

Gastroenterology

Research and Practice
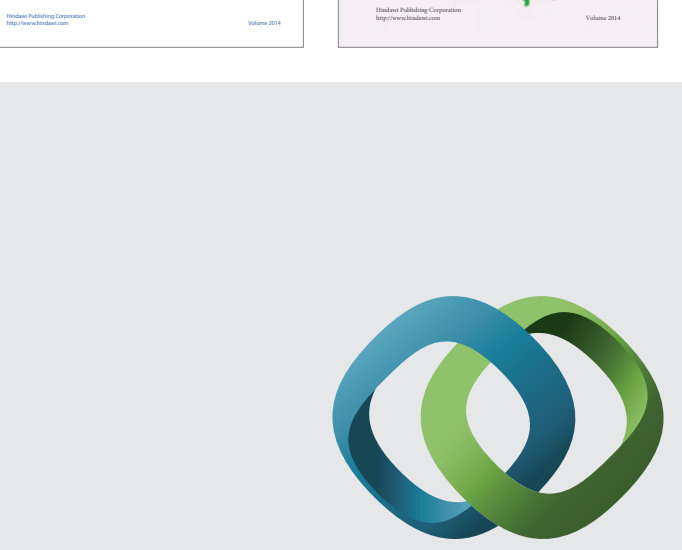

\section{Hindawi}

Submit your manuscripts at

http://www.hindawi.com
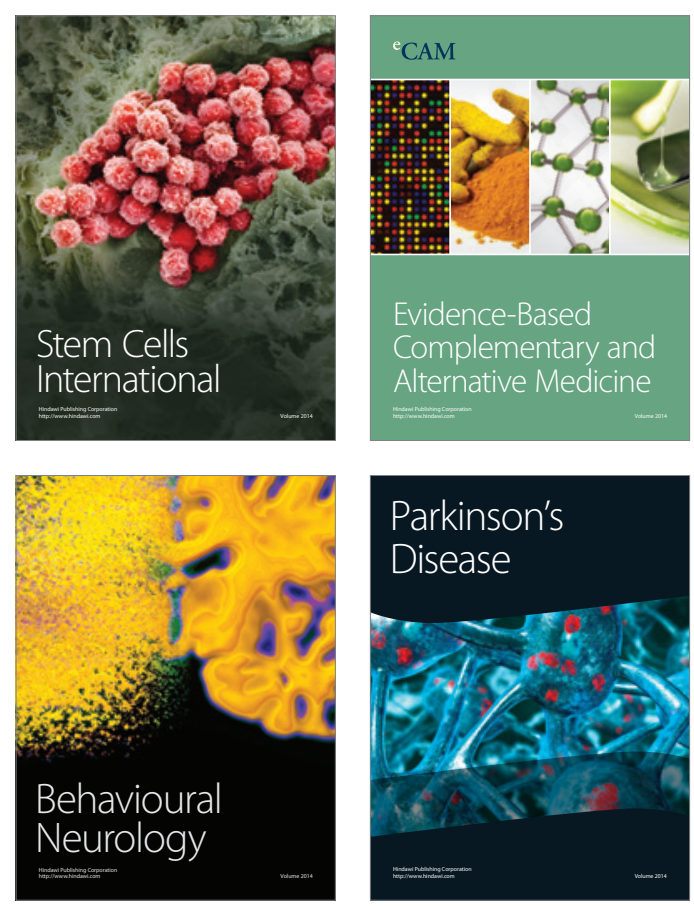

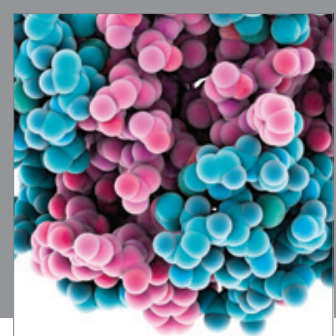

Journal of
Diabetes Research

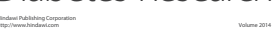

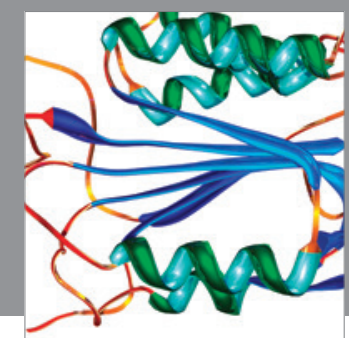

Disease Markers
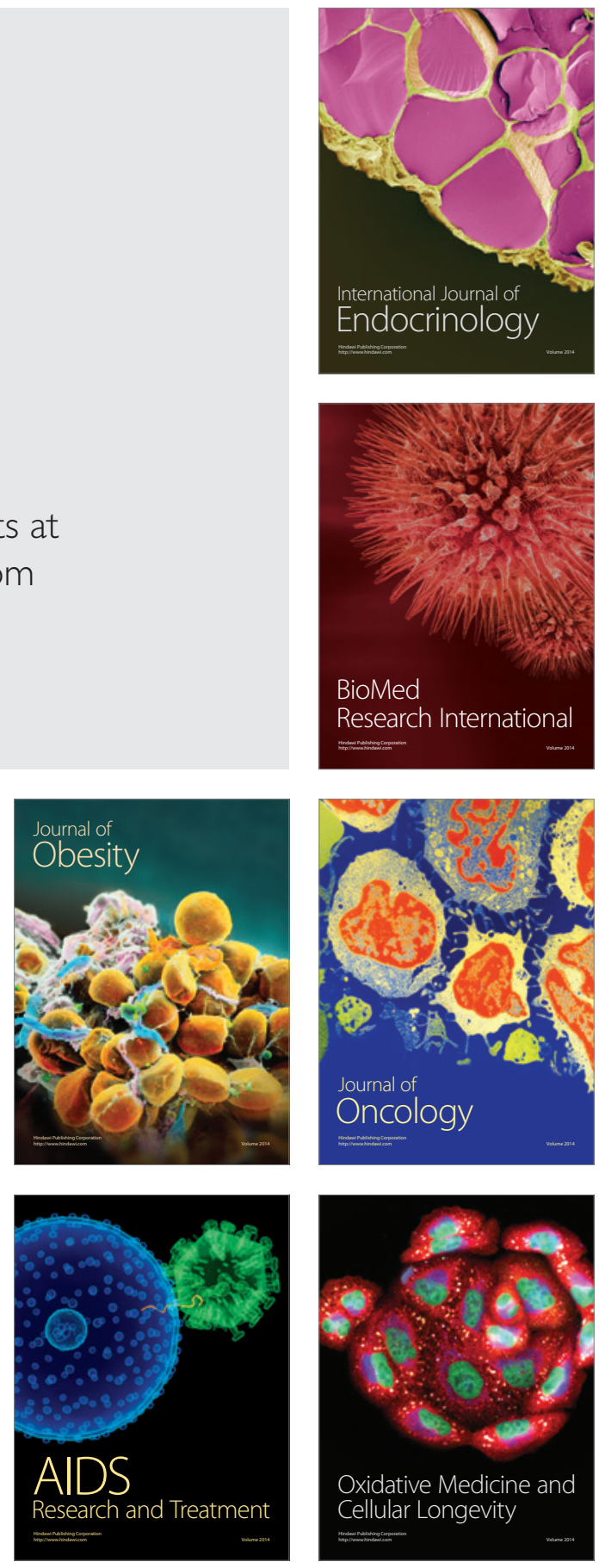